\title{
Research on College English Teaching Reform Based on "Information Processing Learning Theory" Under the Belt and Road Initiative
}

\author{
*Bing He \\ School of foreign language, Dalian Jiaotong University, DaLian, China \\ *Corresponding author e-mail: rachelhe2008@163.com
}

\begin{abstract}
Under the belt and road initiative, it is of practical significance to train talents with intercultural communicative competence. We should learn how to deal with cultural conflicts in scientific, objective and tolerant way in economic and cultural exchange activities. China is facing both opportunities and challenges. For college students, it is particularly important to learn English well. Students should not only master the language application ability, but also deeply understand foreign culture. Good intercultural communication ability will have a strong impact on their future work. The theory of information processing learning can build the information processing model of learning and memory, which has strong practicality. It reveals the general rules of students' classroom learning and teachers' classroom teaching, which is helpful to the cultivation of students' learning motivation and emphasizes students' autonomy. This paper briefly summarizes the meaning of intercultural communicative competence, analyzes the restrictive factors of cultivating students' intercultural communicative competence in College English teaching, and puts forward the methods and countermeasures of cultivating students' intercultural communicative competence in College English teaching by applying "information processing learning theory".

Keywords: one belt, one road, College English teaching, intercultural communicative competence, information processing learning
\end{abstract}

\section{INTRODUCTION}

One belt, one road, has been put forward by President Xi Jinping since 2013. The proposal to build a new Silk Road Economic Belt and the maritime Silk Road in twenty-first Century has greatly deepened our policy communication with the "neighbouring countries" and promoted the development of our national culture to a deeper level. Along the "one belt, one road", the language situation of different countries and the language branches are more, which leads to the economic and trade cooperation and cultural exchange of all countries along the route. As a social communication one, language determines its one basic construction of one belt, one road and one key to language training. Under this new background and development opportunity, College English teaching is also being reformed in order to meet the needs of the new era. One belt, one road, is the most important thing for us to cultivate. Therefore, in the process of learning English, students are required to learn how to use the language and fully understand the profound meaning of the language. Cultivating students' intercultural communication ability is not only conducive to students' better mastery of the international language, but also to the communication with foreign language users, vigorously spread the contemporary Chinese culture, and strive to publicize the great achievements of contemporary China's reform and construction, mainly to enter the international mainstream society and mainstream media. We should make full use of market economy means and modern communication methods, and establish the new image of contemporary China, which has built China into an international cultural centre based on the Asia Pacific region.

\section{AN OVERVIEW OF INTERCULTURAL COMMUNICATIVE COMPETENCE AND ITS SIGNIFICANCE}

Intercultural communication ability is the integration of language knowledge, thinking cognition and social practice at a specific level and to a certain extent. The three elements of spiritual life, social life and material life are interdependent and indispensable. In short, language knowledge is language symbols, including voice, vocabulary and grammatical structure; thinking cognition refers to the emotional attitude of both parties involved in communication, such as flexibility, cross-cultural awareness and being able to understand and treat objectively and correctly in the face of cultural differences between China and the West; social practice refers to welltrained action force [1].

Every country has its own language. There is a close relationship between language and culture. Culture is the basis of language, and language is the carrier of cultural 
communication. The language and culture of any country are complementary and inseparable. In the process of College English teaching, the cultivation of students' cross-cultural communication ability can better enhance students' understanding of western culture and promote students' English language learning. In the process of English teaching, the cultivation of students' cross language communication ability can improve students' understanding of the history and culture of western countries, and help students to understand the way of thinking of western countries, so as to improve students' humanistic quality and deal with the possible cultural conflicts in the process of communication flexibly. Actively participate in the management of international affairs and strive for more voice for the country. It can become a one type of talents with one belt, one road and a national development strategy.

\section{FACTORS RESTRICTING THE CULTIVATION OF STUDENTS' INTERCULTURAL COMMUNICATION ABILITY IN COLLEGE ENGLISH TEACHING}

One belt, one road, requires English talents to be concentrated on intercultural communication. This requires English teaching to focus on cultivating students' solid language skills and language adaptability, deep national cultural accumulation, flexible communication skills and intercourse style, and just perfect cultural adjustment and adaptation. [2] In view of the new requirements put forward by the national development strategy for college students, there are still constraints on the cultivation of students' intercultural communication ability in university teaching

\subsection{Lack of intercultural communication awareness and learning ability of College Students}

The cultivation of English talents in Colleges and universities in our country has always continued the traditional teaching form, and the examination oriented education remains serious. We pay too much attention to students' mastery of English theoretical knowledge, but ignore the improvement of students' ability in practice. Under the influence of traditional teaching methods, we have neglected the importance of cross-cultural learning in improving our English quality and ability. Many students are influenced by the examination and the future development needs. The purpose of learning English is only to pass the CET-4 and CET-6, and they recite the words and memorize the grammar blindly in the learning process. They lack the understanding and learning of the English cultural background such as the daily life habits and eating habits of the British and American countries.
In terms of reading ability, many college students can't read. It is because it has great practical difficulties in the process of English learning, for example, it can't read words, it can't split sentences, it can't translate and so on. Even if it wants to read and dare to read, but all kinds of practical learning difficulties make it unable to speak. In the actual English teaching process, it is the main difficulty for college students to be unable to read. No matter the learning of words, sentences or articles, we always adhere to the way of "cramming textbooks and memorizing", which is inefficient. [3] As a result, it is difficult for students to really understand the cognitive system of English culture, and lack of attention to intercultural communication learning, which to a certain extent affects students' use of intercultural communication and expression.

\subsection{Lack of teachers' understanding of the importance of intercultural communication ability and lack of intercultural experience}

Language and culture complement each other and are inseparable, but many college English teachers often neglect the cultivation of students' intercultural communication ability in the teaching process. Most of the teachers pay more attention to students' learning of English language in the process of English teaching, but neglect students' learning of English culture. English teachers have no experience of studying abroad, which will lead to a lack of understanding of foreign culture. As a result, it is difficult for teachers to carry out cross-cultural communication in the process of English teaching. Due to the lack of corresponding cross-cultural communication experience, teachers will also affect the cultivation of students' cross-cultural communication ability.

Even if some teachers have the awareness of cross-cultural communication training, in College English teaching, it is still limited to the teaching mode of teaching introduction and background knowledge introduction. The Chinese and Western cultural factors involved in the teaching are only fleeting until now, failing to play the active role of students, failing to make full use of inquiry, task-based and project-based teaching methods to develop students' independent learning potential, Failed to train them to acquire knowledge and demonstrate their ability to learn. In the process of teaching, students seldom create situations to think, explore and solve the problems caused by cultural differences. Although cultural courses have been set up in the stage of College English improvement, the cultivation of cross-cultural awareness and ability does not run through the whole process of teaching, and does not change the tacit learning of cross-cultural knowledge and skills into the explicit learning. [4] 


\subsection{The theory of intercultural teaching is not perfect}

At present, in China's higher education, colleges and universities have not yet realized the importance of English teaching process to the cultivation of students' intercultural communication ability, and the corresponding teaching theory is not perfect. As a result, it leads to the cultivation of cross-cultural communication ability and less practical application in the teaching process. In College English teaching, students are usually taught in the traditional mode, focusing on English grammar and vocabulary teaching, adopting the indoctrination teaching method, which is usually said by teachers on the stage and recorded by students on the stage, neglecting the main position of students to a certain extent. Moreover, the separation of English language teaching and culture teaching results in the lack of thinking ability and autonomous learning ability of students in the process of English learning, which leads to the lack of cross-cultural communication awareness of students.

\section{THE STRATEGY OF CULTIVATING INTERCULTURAL COMMUNICATION ABILITY UNDER THE THEORY OF INFORMATION PROCESSING LEARNING}

\subsection{Information processing learning theory}

Gagne is recognized as a representative of the combination of behaviourism learning theory and cognitive learning theory. On the one hand, he recognized that the basic unit of behaviour is the connection between stimulus and response; on the other hand, he focused on the intermediary factor between stimulus and response cognitive activity. Gagne's theory of information processing learning is based on the theory of accumulation learning. Its basic view is that learning any new knowledge and skills is based on the knowledge and skills that have been acquired and belong to them. It includes eight learning levels: (1) signal learning; (2) stimulus response learning; (3) action chain; (4) Speech Association; (5) discrimination learning; (6) concept learning; (7) rule learning; (8) problem solving or advanced rule learning. Higher level learning must be based on the first level learning, so when designing teaching strategies, it can be the basis to form the most effective teaching mode. Gagne thinks that the best way to design teaching is to arrange teaching work according to the expected goal. He proposed five kinds of learning results: (1) speech information; (2) intelligence skills; (3) cognitive strategies; (4) attitude; (5) motor skills. According to the theory of information processing, Gagne puts forward the basic mode of learning process, which is regarded as an information processing process. That is, the process of learners' internal cognitive processing of information from environmental stimuli. [5]

\subsection{Strategies for cultivating intercultural communicative competence}

\subsubsection{Motive stage}

In teaching, teachers should give priority to how to stimulate students' learning motivation. It is established with the help of a psychological expectation generated by students, that is, an expectation of learning results, which points out the direction for subsequent learning. First of all, we must establish a correct concept of cross-cultural communication, be good at absorbing western advanced culture, and extract the essence and the dross. We should avoid blind worship of western culture and establish correct cultural values.

\subsubsection{Understanding stage}

Learning must pay attention to learning related stimuli. When students differentiate learning stimuli from other stimuli, these stimulus features are encoded and stored in short-term memory. This process is selective perception. In the process of English learning, cultural background, reading mode and thinking mode are mutually supporting and influencing. In order to improve their English learning ability, they must master cultural knowledge and thinking mode, actively understand foreign culture and cultivate their cross-cultural communication awareness.

\subsubsection{Acquisition stage}

This stage refers to the process of encoding and storing the newly acquired information in short-term memory, and then further processing into long-term memory. In English learning, teachers consciously guide students to improve their understanding of cultural differences and the mastery of cross-cultural communication skills, provide students with a certain timeliness and targeted teaching materials and learning paths, encourage students to continuously improve their knowledge and skills driven by goals, and carry out selective and efficient input. In this stage, it is necessary to avoid too much one-time information, improper coding time and method, and constantly stimulate students' learning confidence and initiative.

\subsubsection{Recall stage}

The information acquired by students is often expressed through homework, that is, the stage of information extraction and recall. Teachers can use a variety of 
methods to give students clues to extract information. The creation of culture is the sum of human spiritual wealth. The cultivation of the ability of learning and thinking required by cross-cultural English acquisition needs to exercise their language sensitivity in a large number of reading and recitation, so as to help them understand the cultural background quickly and improve their ability of reading, understanding and cross-cultural thinking. In the process of strategy learning and practice, it should be noted that teachers should consciously turn external control into internal control, and guide students to learn self-study.

\subsubsection{Operation stage}

The important function of homework is to help teachers get feedback. At the same time, students can see the results of their study through homework, so as to gain confidence and satisfaction. At present, the evaluation standard of College English is still based on the test scores. This traditional evaluation standard is not only difficult to stimulate students' enthusiasm and interest in learning, but also difficult to adapt to the modern evaluation standard. Therefore, teachers can develop the evaluation mechanism of intercultural communication ability. Through the evaluation between teachers and students or between students, it is conducive to the cultivation of students' communication ability, so that students can learn from each other and make progress in the evaluation process.

\subsubsection{Feedback stage}

When students finish their homework, teachers need to give feedback to let students know the results of their homework in time, so as to strengthen learning motivation. Students can also fully realize the shortcomings of their intercultural communication ability through the feedback results, so as to improve the shortcomings and problems in time and effectively. We should really promote the students to enhance the sense of identity of the Chinese nation, enhance their appreciation of the cultures of various countries, enhance their cultural identity, strengthen their cultural self-confidence, and promote the continuous improvement of their cross-cultural communication ability.

\section{CONCLUSION}

Generally speaking, the reason why there are differences between Chinese and Western cultures is the result of many external factors. But it is precise because of these cultural differences between Chinese and Western languages, which both have their own unique charm. Therefore, in the process of College English teaching, we should use information processing learning theory reasonably, formulate cross-cultural communication ability training strategies, promote students to deeply understand the differences between the two in cultural background, historical development and evolution. We should find out the unique personality between the two languages, combine it with specific English teaching, and integrate it into the "belt and road". In the all-round development, we should formulate corresponding English teaching strategies to cultivate students' intercultural communication ability.

\section{REFERENCES}

[1] Lei Yuanyang. A study on Strategies of intercultural communication in College English Education [J]. Knowledge economy, 2018 (16): 126127

[2] Zhang Wenting. The one of "one belt, one road" training of College English intercultural communicative competence $[\mathrm{J}]$. Journal of Lvliang Institute of education, 2019.36 (3): 72-74.

[3] Zhao Ping. The cultivation of College English reading ability from the perspective of Intercultural Communication [J]. Literature education, 2020,01:124125

[4] Yang Yue, Luan Yuqin, Li Li. Cultivation of intercultural communication ability in output oriented college English teaching $[\mathrm{J}]$. overseas English, 2020,02:144-145

[5] Guo Siping. Gagne's information processing learning theory and its educational model [J]. Jiangxi education, 2004, 1-2:48-49

[6] Zheng Huizhi. A study on the practice of blended teaching mode in College English Teaching [J]. Journal of Jiamusi vocational college, 2019 (07): 167-168

[7] Chen Fei, Chen Wen. Innovative research on English teaching mode of Local Applied Colleges and Universities Based on the perspective of flipped classroom teaching $[\mathrm{J}]$. Journal of Tongling vocational and technical college, 2019,18 (02): 93-97

[8] Cheng Jing. Design of mixed English teaching mode in the context of Internet plus. Study on [J]. English Square, 2019 (05): 110-111.

[9] Sun Qiongqiong. Design and practice of blended teaching mode in the Internet plus background. [J]. literature education (Part 2019), (05): 156-158. 